\title{
Influence of Chinese Traditional Folk Fine Art Graphics on Modern Visual Design
}

\author{
SHENG Ting \\ Wuchang University of Technology \\ Wuchang, China \\ e-mail: shengting199@126.com
}

\begin{abstract}
Chinese traditional folk fine art graphics are rich, bright, diversified and complicated. They contain Chinese traditional philosophy concept and profound cultural background. Chinese modern visual design is greatly influenced by the west world under the trend of globalization. In the paper, influence of Chinese traditional folk fine art graphics on modern visual design is studied. Expression styles and art features of Chinese traditional folk fine art graphics are discussed. Influence of traditional Chinese folk fine art graphics on modern visual design and application of traditional Chinese folk fine art graphics in modern visual design are analyzed.
\end{abstract}

Keywords-Traditional folk fine art; Fine art graphics; Modern visual design; Influence

\section{INTRODUCTION}

Chinese traditional folk fine art graphics are characterized by diversified material categories, various styles, unique narrative mode and free imagination. They have localized art tradition and spiritual resources in China. Turbid art expression method, Yin and Yang five-element philosophy, localized narrative method and profound national culture underground of Chinese traditional folk fine art graphics become treasure as reference for modern visual design in China. Folk fine art and visual design produce differences in regions, eras and nationalities, and their expression forms are different to certain extent. However, both parties share the same survival soil with similar theory foundations, thereby achieving possibility of interaction between folk fine art and visual design.

\section{EXPRESSION TECHNIQUES AND ART FEATURES OF CHINA TRADITIONAL FOLK FINE ART GRAPHICS}

Folk fine art acts as an art produced by daily life creation of social common people. Its production and development are closely related to folk activities and folk culture in China. Folk fine art is widely distributed in different regions of China, arts in different regions are respectively characteristic with ethnic attributes. Folk fine art can be divided into the following categories according to expression technique classification of traditional folk fine art graphics: sculpture, painting, furniture, household utensils, embroidery dyeing or others, such as clothing, paper cutting, food, etc. Folk fine art can be divided into the following major categories according to folk fine art graphics prototype classification: auspicious pattern, phoenix pattern, dragon pattern, pattern of Chinese characters, lace pattern, Chinese zodiac pattern, maid pattern, benevolent pattern and other graphic prototype. These graphics prototypes are mostly produced by folk labor people in China according to social life and natural world. Graphic prototypes can be deduced and processed by observation method and thinking mode with unique ethnic and regional characteristics, thereby the prototypes can become abstract, graphic and fixed art graphic symbols. China ancient civilization is accumulated in these folk fine arts, which are used for expressing collective artistic consciousness under specific culture structure and social culture by China social people, and reflecting China folk culture idea and aesthetic demand. Two techniques of symbolization and implication are mainly adopted for expressing China folk fine art traditional graphics as a whole. Similar concepts are symbolized and implied with intuitive images, thereby expressing some connotation and emotion implied inside the works by creators, such as 'moire', 'jolly meeting', tai chi and other folk fine art graphics.

Folk fine art has unique characteristics in expression techniques on one hand, it also shows art features different from other arts in art on the other hand, which are embodied in the following aspects: firstly, folk fine art integrates both aesthetic feature and practicality. Traditional folk fine art carries on aesthetic temperament of folk people and concept consciousness. They mainly regard vessel and other life articles as carriers with practical properties. Secondly, color and model are lively and concise with strong recognition. Folk fine art is simple with high integrity. Thirdly, complete image graphs are combined in the forms of isomorphism and composition. Folk fine art reflects theme significance and philosophical ideas with national characteristics in special narrative principle and language statement mode. Traditional ethnic culture provides reference and innovation direction for Chinese modern visual art design with unique artistic characteristics, expression technique and design thinking.

\section{APPlication of Chinese Traditional Folk Fine ART Graphics IN MODERN Visual DESIGN}

China traditional folk fine art graphics are provided with unique cultural connotation, rich creation technique and expression forms with rapid development of social economy and rapid increase of multimedia technology. It is applied to various fields of modern visual design, such as poster design, logo design, advertising design, packaging design, etc., and graphic modernity and aesthetic modernity can be reflected by modernized application of China traditional folk fine art graphics. 


\section{A. Application of Chinese Traditional Folk Fine Art Graphics in Poster Design}

Poster design pays attention to creation and pursues novel conception, distinct personality and outstanding visual effect. Chinese traditional folk fine art graphics are applied in poster creation, thereby providing poster works with stronger persuasive and appealing force, and increasing design sensationalism. Poster designers usually combine Chinese traditional folk fine art graphics with western figures, and reserve internal spirit of traditional folk fine art graphics. Modern expression techniques are suitably applied for simplifying heavy and complicated traditional folk approaches, and providing theme with new features. Figure 1 shows poster design work of Mr. Han Binghua. It is a poster designed for Hong Kong Trade Development Bureau with the shape of modern dragon. Traditional and complicated dragon design is not used in modern dragon design made by Mr. Han Binghua. Simple geometric shapes are used for creating dragon in new posture. Circular arcs in different sizes are used for inserting in dragon god. Geometric curves make the poster simple and lively with lifelike sense. When Chinese traditional folk fine art graphics are applied in poster design, the creator should pay attention to spiritual connotation and culture price of thinking traditional art, and strengthen inheritance and promotion of traditional folk art graphics. We should extract essence from traditional culture in face of impact of globalization, thereby poster design can be provided with stronger folk features and personality. Traditional folk fine art graphics, the visual carriers' can be used for producing works capable of embodying culture connotation contained in traditional folk fine art graphics.

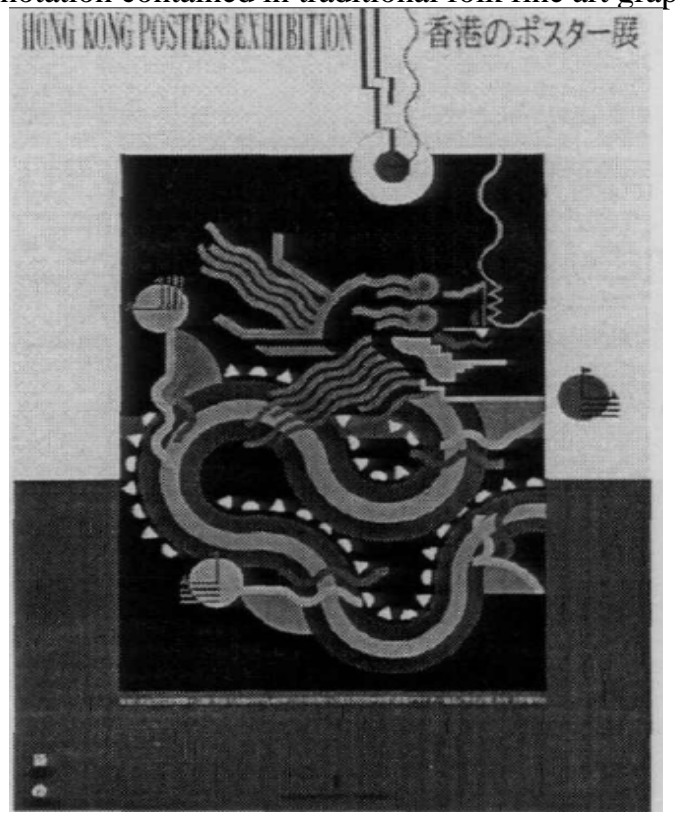

Figure 1. Poster design of Mr Han Binghua

\section{B. Application of Chinese Traditional Folk Fine Art Graphics in Packaging Design}

Chinese packaging design emphasizes celebration, integration and balance because of psychological culture characteristics formed in China for long term. More aesthetic arts are embodied by modern packaging due to changes in economic situation, consumption concept and aesthetic idea. Packaging art becomes a cultural symbol, which can reflect local characteristics. National unique features can be reflected better in packaging design. Many packaging designers integrate traditional folk fine art graphics with modern design, thereby reflecting stronger culture feature and nationality. Tea and moon cake packaging works are shown in figure 2 and figure 3 . Consumers can observe product features and main values from the packaging. Packaging can facilitate consumers in procurement.

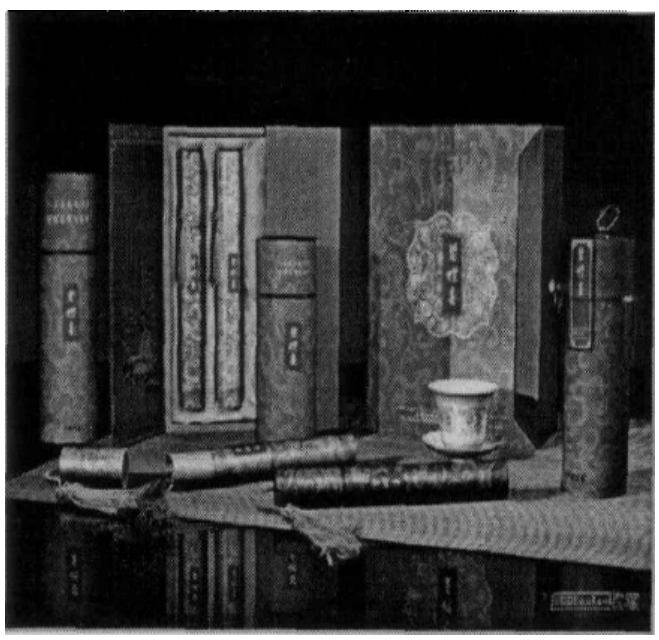

Figure 2. Packaging of tea

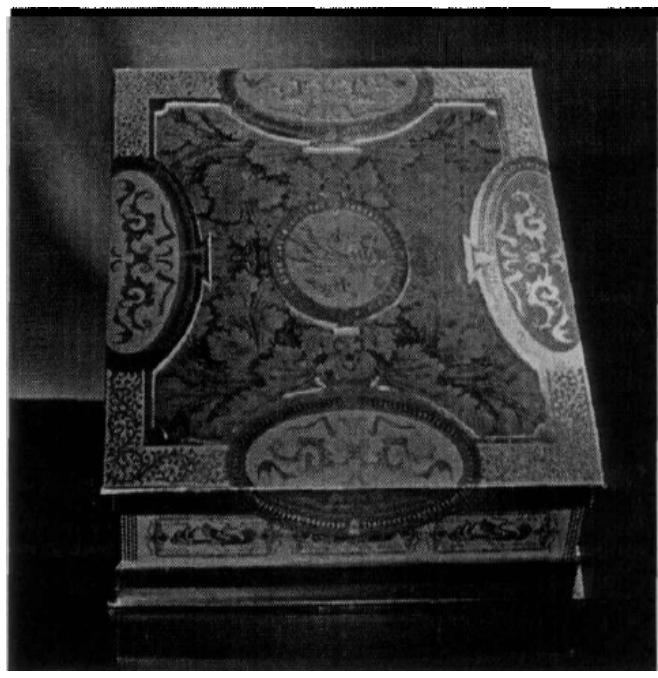

Figure 3. Packaging of moon cake 
China pursued 'integrity of nature and humanity', paid attention to harmony of form, contents, etc. of aesthetic subject and object, and focused on artistic conception, performance and feeling since ancient times. China's thinking of 'integrity of nature and humanity' has greater influence on China modern packaging design. Traditional folk fine art graphics are utilized to reflect national characteristics and traditional features. For example, pens, ink, paper and inkstone are important appliances for ancient scholars during writing, and they contain cultural connotation with more unique artistic quality. These graphics can be utilized in the packaging design for better showing cultural characteristics. Chinese traditional folk fine art graphics are provided with relatively strong life feature and thick symbolic color. For example, graphics of lotus and carp can be utilized as symbols of surplus every year, and they embody yearning of ancient people for a better life. New development of national culture can be promoted by social change and national integration. Converging point of traditional culture and international trend should be discovered in the aspect of packaging design, thereby keeping traditional national culture and encountering impact of globalization synchronously. Therefore, packaging design should focus on absorbing and integrating traditional folk art, and promoting development of packaging culture industry.

\section{Application of Chinese Traditional Folk Fine Art Graphics in Logo Design}

Vivid and perceptual logo design aims at conveying some content and information to people through visual symbol design, thereby visual symbol recipients can appreciate the thoughts and achieve consensus. Logo in Figure 4 integrates continuity of folk culture essence in design with novel shape. It not only emphasizes to embodying surrounding objects, but also contains thought concept, intelligence and corresponding emotion pursuit of folk fine art culture. In logo design, the designer introduces color, graphics and text with Chinese traditional folk fine art culture for communicating with visual symbol receivers. Corresponding culture is interpreted through the form of folk fine art graphics, thereby showing corresponding meanings. In logo design, the design should emphasize and learn to comprehend Chinese folk traditional graphics, understand and recognize manifestation techniques and history source of folk traditional graphic prototypes, thereby extracting their essence. Art value of Chinese folk traditional fine art is fully utilized for realizing promotion of logo meanings.

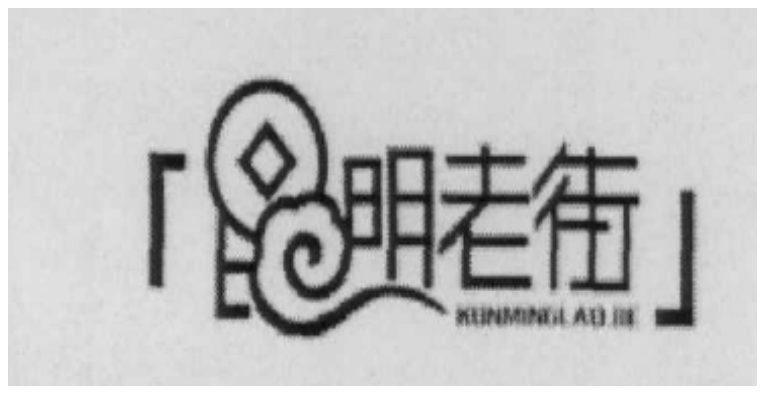

Figure 4. Logo designed for old street in Kunming
Logo design in Figure 4 reflects corresponding folk philosophy concept and Chinese folk traditional mode of images abstracting from viewing through utilizing expression techniques of folk art in China. Artistic conception and charm pursued by Chinese folk fine art are embodied. Chinese folk fine art design and creation produce more far-reaching influence. Logos designed according to China traditional folk fine art mostly reflect integrated and concentrated moral forms of traditional culture, and they are symbol expression of symbolic meaning combining objective images and emotional features of work creators. In addition, Chinese folk fine art is characterized by complete and large spatial integration, unique beauty of connotation and form, and these characteristics are better coordinated and unified with logo design. They have better application prospect in modern logo design, creator should integrate and develop Chinese folk traditional fine art in design and innovation.

\section{INFLUENCE OF CHINESE TRADITIONAL FOLK FINE ART GRAPHICS ON MODERN VISUAL DESIGN}

Chinese history is as long as five thousand years. Therefore, China has traditional art graphics with wide and diversified scope as well as rich connotation. Their art culture has rich connotation, and Chinese traditional folk fine art graphics can provide an unique approach for modern visual design field.

\section{A. Traditional Folk Fine Art Graphics Awaken National Feeling of Modern Visual Design}

It is difficult for diversified modern visual design form to discover realistic self-value in the impetuous a d machinery society that we forget our own properties. Visual design is an important way for people to show emotions and express life. Visual design can subtly affect people's emotional concept. Chinese traditional folk fine art graphics contain auspicious message and unique art. They are expression forms of national essence brightness in China. Chinese traditional folk fine art graphic belongs to a maternal origin art. Traditional folk fine art graphics are integrated in the visual design for better waking up memories lost by people in modern society, and they can find own spiritual sense of belonging.

\section{B. Chinese Traditional Folk Fine Art Graphics Can Inspire Creation Inspiration of Modern Visual Design}

Visual designers can stimulate creation inspiration in traditional folk fine art graphics because of profound cultural implication, graphic resources, etc. contained in traditional folk fine art. In addition, folk fine art, as a graphic symbol from daily life of social people. It contains universal aesthetic tendency of the majority of people itself. Specific visual symbols accepted by the people are gradually formed, therefore folk art graphic symbols are characterized in that they have large amount of information and can be quickly comprehended and accepted by people. The characteristics are just in line with requirements on visual design. Visual designers should inherit and recreate the graphics. Chinese folk fine art embodies Chinese traditional national culture well. The visual designers integrate Chinese folk fine art in 
visual design creation, thereby exerting the feature of folk fine art spiritual concept with rich connotation sufficiently. Works can be provided with high social feature and national culture. Visual designers also can regard folk fine art as the breakthrough point and carrier. Desired meaning of visual work can be promoted through the art form of folk fine art, and creativity of visual design can be stimulated by integrating with folk art.

\section{Chinese Traditional Folk Fine Art Graphics Can Satisfy Personalized Demands of Modern Visual Design}

Chinese traditional folk fine art graphics contain yearning and worship on nature, which respect concept of integrating natural and humanity. Visual design aims at the public, thereby producing diversified demands on visual design. Visual design can achieve existence value by being recognized by most people. In addition, people have stronger and stronger personalized demand with the development of the times and economy progress. Chinese traditional folk fine art graphics are passed through history accumulation and history recognition. Therefore, art feature of traditional folk fine art graphics can be extracted in visual design, national personality can be kept, and the designed work can advocate own ideology more deeply. Therefore, visual design works can achieve unique personality and recognition from people.

\section{CONCLUSION}

Chinese traditional folk fine art belongs to folk art embodying art tradition and local culture spirit with high influence on modern visual design. It is widely applied in many fields of modern visual design. Chinese traditional folk fine art graphics can awaken national feeling of modern visual design, inspire creation inspiration of modern visual design, and satisfy personalized demand of modern visual design. However, deeper research is required for traditional folk fine art graphics. Modeling structure, culture background and spirit original traits should be deeply explored. Digestion and absorption of traditional folk fine art graphics should be strengthened and recreated, therefore it can achieve national characteristics. It also can become internationally recognized modern visual design.

\section{REFERENCES}

[1] Chen Chao, "On modernized transformation of traditional folk fine art,” Journal of Anhui Literature (second-half monthly). 2010 (6).

[2] Jiang Dengpan. "On inheritance and innovation of traditional folk fine art in China modern design ,” Art Education. 2011 (04).

[3] Han Xiang, Jiang Yuwen. "Study of Chinese traditional folk fine art win-win situation of finance and art ,” Art and Design (Theory). 2014 (Z1).

[4] Wang Zhouhai, "Influence of Chinese folk paper-cutting art on modern design ,” Art and Design (Theory), 2010 (7) .

[5] Fu Jiannan, “Application of graphic symbol in graphic design,” Guide to Business. 2011 (14).

[6] Chen Binglong. "Analysis on inheritance and development of Chinese folk fine art ,” Journal of Mudanjiang Education College. 2013 (6).

[7] Zhou Dapeng, "Factors affecting spread of Chinese folk fine arts education,” Journal of Sanmenxia Vocational and Technical College. 2009 (3).

[8] Yi Yan, “Introduction to Chinese Folk Fine Art," Journal of Intelligence. 2010 (17).

[9] Liu Yi, “On inheritance and development of Chinese folk fine art," Journal of Intelligence. 2013 